\title{
COMPARATIVE EFFECTS OF BORIC ACID AND RESVERATROL ON MCF-7 BREAST CANCER CELLS METASTATIC BEHAVIOUR
}

\author{
Fatma Firat ${ }^{1} \bowtie(D)$, Tuğçe Aladağ $2 \bowtie$ (iD \\ ${ }^{2}$ Department of Histology and Embryology, Faculty of Medicine, Afyonkarahisar Health Sciences University \\ Afyonkarahisar, Turkey.
}

Received 01 December 2021

Accepted 26 December 2021

Published 31 January 2022

\section{CorrespondingAuthor}

Tuğçe Aladağ,

tugcealadagg@hotmail.com

DOI

10.29121/granthaalayah.v10.i1.2022 .4460

Funding: This research received no specific grant from any funding agency in the public, commercial, or not-for-profit sectors.

Copyright: (C) 2022 The Author(s). This is an open access article distributed under the terms of the Creative Commons Attribution License, which permits unrestricted use, distribution, and reproduction in any medium, provided the original author and source are credited.

\section{ABSTRACT}

Motivation/Background: The metastasis of tumor cells consists of steps such as epithelial-mesenchymal transition, transendothelial migration and the formation of metastatic colonization. E-Cadherin and vimentin are main proteins associated with EMT, whereas MMP-9 is associated with migration.

Method: We aimed to investigate effects boric acid and resveratrol comparatively on metaatatic behaviors on MCF-7. $30 \mu \mathrm{M}$ boric acid and $50 \mu \mathrm{M}$ resveratrol were administered to BA, BA+RES, and RES groups 48hours. Cells stained immunocytochemically by Anti-E-Cadherin, Anti-Vimentin, and Anti-MMP-9 antibodies and $\mathrm{H}$-Score analysis carried out and migration analyzed by woundhealing, morphologically.

Results and Conclusions: It's been observed that boric acid doesn't affect the EMT capability of the MCF-7 cells in terms of E-Cadherin and vimentin expression; whereas it's affected migration both by decreasing the MMP-9 expression and also by inhibiting migration.

Keywords: Boric Acid, MCF-7 Breast Cancer, Epithelial-Mesenchymal Transition, Metastasis, Resveratrol.

\section{INTRODUCTION}

Breast cancer is a type of cencer which has the highest mortality rates and is the most common cancer in women Global Cancer Observatory (2021). There are novel therapeutic approaches being developed in breast cancer treatment nowadays Mahjoubin-Tehran et al. (2020). Despite this, there is still need for effective methods in terms of cencer treatment. In general, deaths based on cancer is mainly caused by metastasis Dillekås et al. (2019). Banfalvi (2012) believes that the development of breast cancer is mainly metastasis rather than the primary tumor and states that the main reason of death caused by breast cancer is tumor invasion and metastasis Banfalvi (2012). 10-15\% of patients usually have metastasis during the three years following the first treatment. Metastasis includes stages such as local invasion (Epithelial-Mesenchymal Transition (EMT)), intravasation, survival in the circulation, extravasation (transendothelial migration (TEM/diapedesis)), the development of micrometastasis and the development of metastatic colonization Reymond et al. (2013). Metastasis in cancer cells is a complex process directed by a great number of biochemical and molecular factors. Although this process and the mechanisms of action are not completely enlightened, the chance to eliminate the disease will arise if the cancer cells can be stopped in the invasion stage. 
Invasion occurs when cell-cell and cell-matrix interactions are damaged. Cadherin, one of the cell-cell adhesion proteins, takes the leading role in this process. While NCadherin shows an increase in the gastrulation period, is higly found in mesenchymal cells and is the cadherin which is accepted as the marker of EpithelialMesenchymal Transition (EMT); in methastatic breast cancer, the decrease in ECadherin expression is9 the hallmark of invasion Özkara et al. (2020). Studies on breast, pancreas, lungs, and bladder cancer cells have shown that cells that have normal E-Cahedrin expression display epithelioid phenotype and are not invasive; whereas cells that have low-expression of E-Cahedrin display fibroblast-like phenotype and are invasive Farahani et al. (2014). Moreover, proteins that are essential for extracellular matrix (ECM) degradation and tumor invasion such as matrix metalloproteinase (MMP) - 1 and MMP-9 play an important role in metastasis and consequently in the course of the disease. Some studies have shown an overexpression of MMP-9 in breast cancer cells and have reported that it is effective in cancer metastasis and invasion Jones et al. (1999), Westermarck and Kähäri (1999).

Both in vivo and in vitro studies have shown that resveratrol (RES), which is a polyphenol naturally found in grapes and red wine, has anti-cancer properties and delays carcinogenesisBaur and Sinclair (2006), Signorelli and Ghidoni (2005). Chen et al. (2019) and Xu et al. (2017) have shown in their in vitro studies that in breast cancer and gastric cancer cells, resveratrol changes protein expressions that play a role in mesenchymal transition such as E-Cadherin and Vimentin Chen et al. (2019), Xu et al. (2017). Likewise, in the year of 2021, Chang et al., (2021) have reported that the application of $50 \mu \mathrm{M}$ Resveratrol decreases the expression of MMP-9 protein in cancer cells Chang et al. (2021). Boron, a trace element for organisms, has high affinity to oxygen and nature is filled with plenty of borates such as in the forms of boric acid and borax Devirian and Volpe (2003). Boric acid, which has a soluble boron form, can easily be taken into the human body by food and drinks. Following the intake of a boric acid in diet, it is absorbed by the gastrointestinal system which is then passed on to the blood circulation and it plays a role in several physiological and biochemical events due to its antioxidant or anti-cancer properties Barranco et al. (2007), Pawa and Ali (2006) . Most cancer studies that are carried out with BA have focused on the aspect of its cytotoxic effect Aydin et al. (2021), Hacioglu et al. (2020). Nonetheless, in literature there are not quite enough studies on boric acid's effect on the EMT capabilities of cancer cells. In this study, we have examined in vitro boric acid's effect on MCF-7 breast cancer cells in terms of cell migration, metastasis, and morphology in comparison to resveratrol.

\section{MATERIALS AND METHODS \\ 2.1. PREPARATIONS OF CHEMICAL SOLUTIONS}

Resveratrol (TCI-R0071, TCI AMERICA) was solved into $100 \mu \mathrm{M}$ of medium Leon-Galicia et al. (2018), Schmidt et al. (2020) as a IC 50 dose which was determined according to the published reports Leon-Galicia et al. (2018), Schmidt et al. (2020). MTT test was done for boric acid and solved into an $\mathrm{IC}_{50}$ dose of $30 \mu \mathrm{M}$ in a medium preheated to $37^{\circ} \mathrm{C}$ was used.

\subsection{CELL CULTURES}

MCF-7 breast cancer cells were used for the study (ATCC, USA). Cells were cultured in RPMI-1640 medium including 10\% Fetal bovine serum (FBS), 1\% LGlutamin and $1 \%$ antibiotics (penisilin-streptomisin) and incubated at $5 \% \mathrm{CO}_{2}$ density and $37^{\circ} \mathrm{C}$ during the experimental period of 2 days. When the cells reached 
the confluency number of $80 \%$, they were divided into 4 groups as follows: Boric acid (BA), boric acid+resveratrol (BA+RES), resveratrol (RES) and control (CONT) groups and the cells were treated by the effective substances (boric acid and resveratrol) for 48 hours.

\subsection{DETERMINATION OF CELL VIABILITY USING MTT ASSAY}

To determine the cytotoxic effect and $\mathrm{IC}_{50}$ dose of boric acid on cells, 3-(4,5Dimethylthiazol-2-yl)- 2,5-Diphenyltetrazolium Bromide (MTT) assay was carried out. For resveratrol, the $\mathrm{IC}_{50}$ dose was used in accordance to the literature Leon-Galicia et al. (2018), Schmidt et al. (2020) . MCF-7 cells were cultured in 96well plates with a density of $2 \times 10^{4}$ cells per well and following the cells' adherence, different concentrations of boric acid $(10,30,50$ and $100 \mu \mathrm{M})$ were exposed to cells for 48 hours. At the end of 48 hours, MTT (Sigma-Aldrich) solution prepared in accordance with manufacturer's instructions was added to each well as $20 \mu \mathrm{L} /$ well and incubated at $37{ }^{\circ} \mathrm{C}$ for 4 hours. Following 4 hour of incubation, MTT was removed and $200 \mu \mathrm{L}$ of dimethyl sulfoxide (DMSO) was added to each well. Then they were incubated on the shaker in a dark room for 5 minutes and the absorbance values were measured at a wavelength range of 570-690 nm with a microplate reader (Shımadzu UV-1601). Three wells were used for each concentration and each measurement was repeated seven times.

\subsection{ANALYSIS OF CELL MORPHOLOGY}

To analyze cell morphology, the cells were visualized at the time points of $0^{\text {th }}$ (zero) and $48^{\text {th }}$ hours following the treatments of the substances under the phaseconstrast microscope (ZEISS Primo Vert iLED).

\subsection{IMMUNOCYTOCHEMICAL METHODS}

At the end of 48-hour treatments, the cells in each group were washed with PBS once and fixed with 4\% paraformaldehyde for 30 minutes. After fixation 3\% hydrogen peroxide $\left(\mathrm{H}_{2} \mathrm{O}_{2}\right)$ was applied for 5 minutes followed by washing 3 times with PBS each taking five minutes again. Then it was incubated in $0,1 \%$ Triton-X 100 for permeabilization for 15 minutes. After the washing, an hour of protein blockage and then the incubation with anti-E Cadherin (1/200, ab76055, abcam), antiVimentin (1/200, ab8978, abcam) and anti- MMP-9 antibodies (1/200, ab76002, abcam) were carried out overnight at $+4{ }^{\circ} \mathrm{C}$. Following the incubations, the secondary antibodies were applied, and immunoreactivity was visualized using DAB (3,3'Diaminobenzidine) chromogen. Finally, covering medium was added and the pictures were taken under light microscope (NIKON Eclipse E600) using the Image Analysis Program (NIS elements, Japan). Following immunohistochemical staining, $\mathrm{H}$-Score assessment which is a semiquantitative method was performed for statistical analysis. H-score: for each group, 500 cells were counted for each region. Based on the intensity of the cellular staining; using the formula of the total cell number stained being as (\%) X (staning intensity 0, 1,2,3,4,5) H-score were evaluated between 0 - 500 Numata et al. (2012).

\subsection{WOUND HEALING ASSAY}

Once MCF-7 breast cancer cells (ATCC) were 100\% confluent, the treatments were carried out to the designated groups and a wound field were generated in the middle by making a gap with the help of a $10 \mu$ l-sterile pippete tip. To compare the migration tendencies of the cells towards the wound field to close it and their 
velocities during these migrations, the pictures were taken from each group using a phase-contrast microscope for twelve-hour intervals and evaluated comparatively Zhang et al. (2019).

\subsection{STATISTICAL ANALYSIS}

$\mathrm{H}$-score assessment data were analyzed by using binary comparison test (Kruskal Wallis test) using SPSS 20.0.(Table 1).

\subsection{ETHICS COMMITTEE APPROVAL}

The cells used in the study are commercially available, so ethics committee approval is not required.

\section{RESULTS}

\subsection{ANALYSIS OF THE EFFECT OF BORIC ACID ON CELL VIABILITY USING MTT ASSAY}

To decide the $\mathrm{IC}_{50}$ dose of boric acid in MCF-7 cells, the level of viability was determined using MTT assay. Boric acid doses of $10,30,50$ ve $100 \mu \mathrm{M}$ to the MCF-7 cells were administered for 48 hours. At the end of this 48-hour period, it was observed that 48-hour administration of $100 \mu \mathrm{M}$ dose of boric acid abolished cell viability completely. Viability in MCF-7 cell groups decreased by approximately $81 \%, 54 \%$ and $27 \%$ at 10,30 and $50 \mu \mathrm{M}$ doses of boric acid, respectively. Therefore, the $\mathrm{IC}_{50}$ dose of boric acid for MCF-7 cells were determined as $30 \mu \mathrm{M}$ and administered to the study groups in other stages (Figure 1). No dose determination tests were done for resveratrol since sufficient studies were done previously.

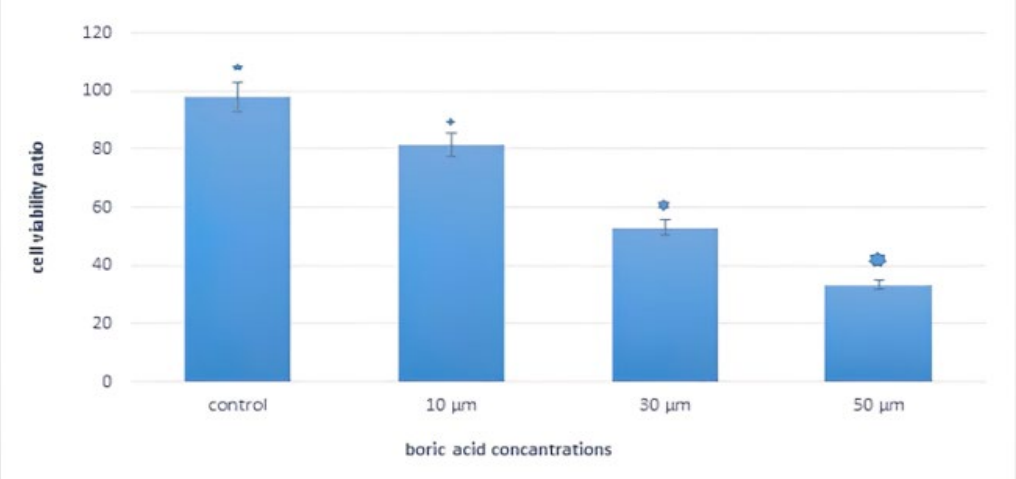

Figure 1 MTT analyzes of the effects of boric acid administration on cell viability in MCF-7 cells

\subsection{CELL MORPHOLOGY}

MCF-7 breast cancer cells were incubated for 2 days. When the cells reached $80 \%$ of confluency, they were divided into groups and the doses determined as a result of MTT assays of boric acid (BA), resveratrol (RES) and boric acid + resveratrol (BA+RES) together were administered for 48 hours. Before treatment, all MCF-7 cells in all study groups and the control group were observed to have an epitheloid morphology except for a few of them having a round structure as well as the fact that their cell membrane boundries were visible the structure of the nucleus and cytoplasm were normal (Figure 2A). After the treatment for 48 hours, it was 
noticed that cell morphology in BA, RES and BA+RES groups was round shaped like apoptotic cells as well as having nuclear condensation and noticeable morphologic changes in the cytoplasm such as vacuolization. These cells with apoptotic properties were observed to be higher in number in BA and BA+RES groups in comparison to CONT and RES groups. However, vacuolization and nuclear condensation increased in cells in the RES group while no noticeable changes in cell morphology was seen (Figure 2), Gharagozloo et al. (2015).

Table 1 Immunocytochemical analyses of E-Cadherin, Vimentin and MMP-9 in control, Boric acid, Boric acid+Resveratrol and Resveratrol groups were given mean \pm SD values

\begin{tabular}{ccc}
\hline ANTIBODY & GROUPS & $\mp$ SS \\
\hline E-CADHERIN & BA & $496 \mp 4,35^{\mathrm{ac}}(497)$ \\
& BA+RES & $1103 \mp 3,71^{\mathrm{b}}(1103)$ \\
\hline VIMENTIN & RES & $1467 \mp 2,73^{\mathrm{bc}}(1467)$ \\
\hline & CONT & $738 \mp 2,30^{\mathrm{a}}(739)$ \\
\hline MMP-9 & BA+RES & $1714 \mp 2,73^{\mathrm{bc}}(1714)$ \\
& RES & $1984 \mp 2,38^{\mathrm{b}}(1984)$ \\
& CONT & $1074 \mp 2,86^{\mathrm{a}}(1074)$ \\
\hline & BA & $1348 \mp 3,56^{\mathrm{ac}}(1350)$ \\
& BA+RES & $984 \mp 2,73^{\mathrm{ac}}(984)$ \\
& RES & $923 \mp 3,03^{\mathrm{a}}(923)$ \\
\hline & CONT & $1173 \mp 3,36^{\mathrm{bc}}(1173)$ \\
\hline
\end{tabular}
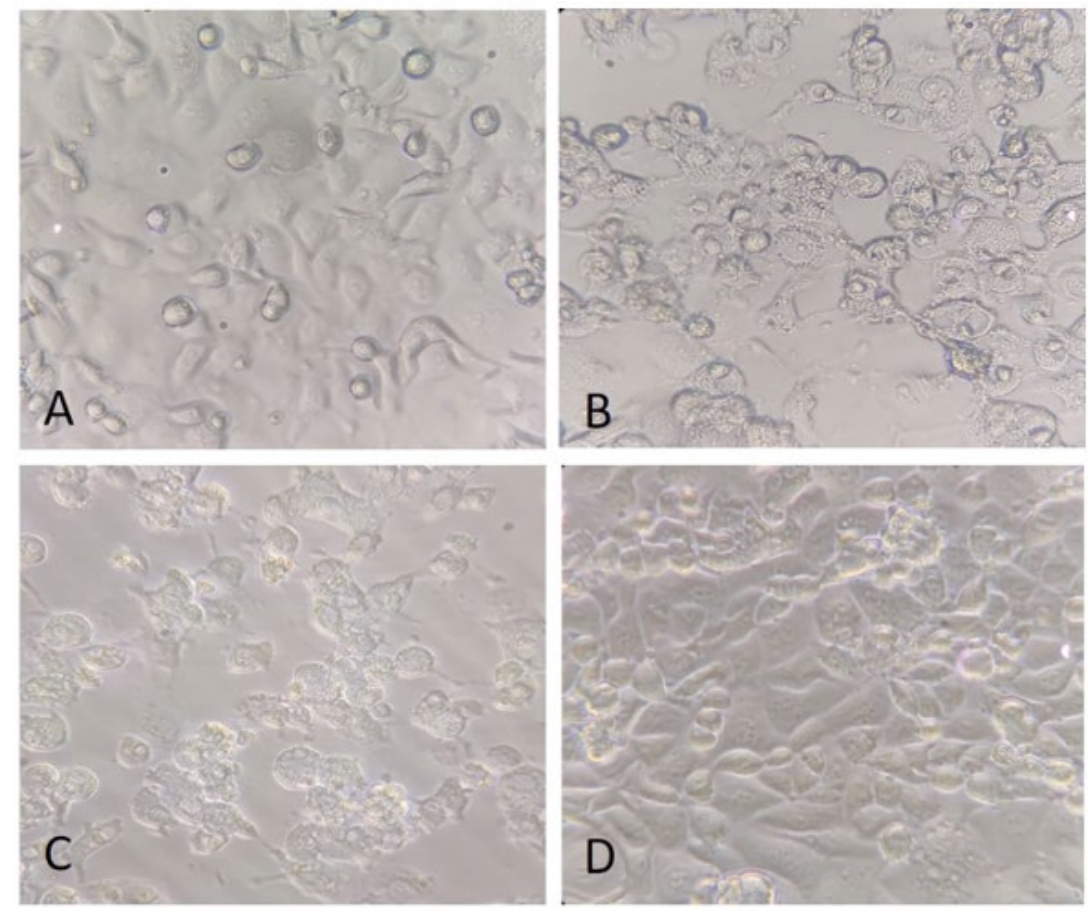

Figure 2 Morphology of MCF-7 cells in various groups (All magnifications are $\mathrm{x} 400$.). Morphological changes seen after 48 hours of application of Boric acid, Boric acid+Resveratrol and resveratrol to the cells. A) Control group; B) Boric acid; C) Boric acid+ resveratrol; D) Resveratrol (400x magnification). 


\subsection{EFFECTS OF BORIC ACID AND RESVERATROL ON EMT}

To analyze the effect of boric acid and combined Boric acid + Resveratrol on epithelial-mesenchymal transition (EMT) proteins, boric acid, combined boric acid + resveratrol and resveratrol treatments were done in MCF-7 cells for 48 hours. The control group was considered as the group with no treatments at all. After treatments, the changes in Vimentin and E-Cadherin protein expressions were analyzed immunocytochemically and $\mathrm{H}$-Score analysis were carried out (Figure 3). E-Cadherin immunoreactivity was found to be higher in the RES group $(p=0,04)$ compared to the CONT group, while E-Cadherin protein expression levels in BA and BA+RES groups were observed to be increased slightly in comparison to the CONT group ( $p>0,005)$. H-Score analysis revealed that Vimentin immunoreactivity was observed to be increased in the BA+RES group showing a higher protein expression compared to the control group $(\mathrm{p}=0,008)$. However, the change in the intensity of immunoreactivity in RES and BA groups was not significantly different compared to the control group $(\mathrm{p}>0.05)$.

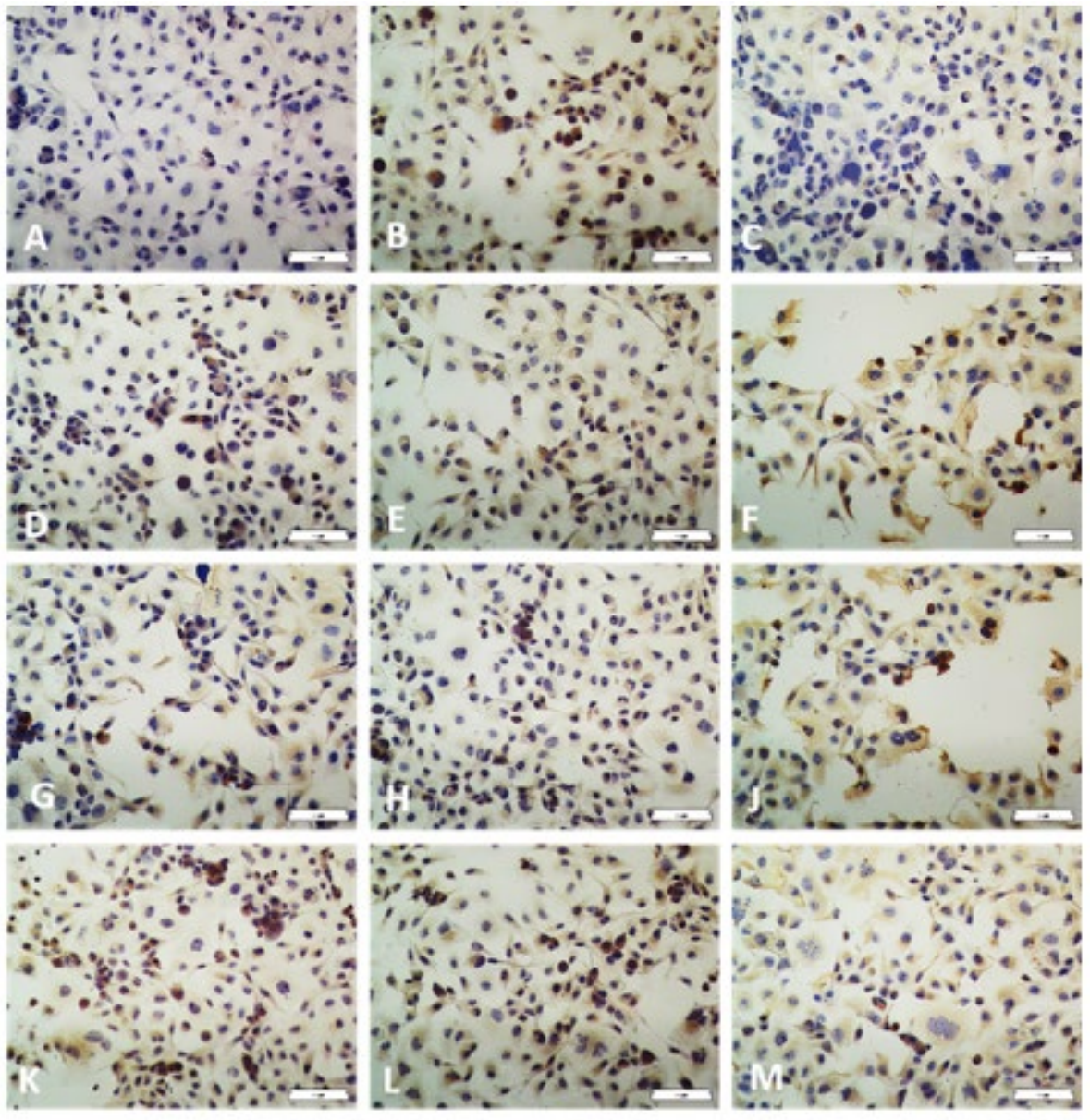

Figure 3 Immunohistochemical clearances of E-Cadherin, Vimentin and MMP-9 immunoreactivities. (Scale bar $100 \mu \mathrm{m}$ ). The vertical column groups and the horizontal row indicate the antibodies used. E-Cadherin stain: A) Control group; D) Boric acid; G) Boric acid+ resveratrol; K) Resveratrol. MMP-9 stain: B) Control group; E) Boric acid; H) Boric acid+ resveratrol; L) Resveratrol. Vimentin stain: C) Control group; F) Boric acid; J) Boric acid+ resveratrol M) Resveratrol (200x magnification). 


\subsection{EFFECTS OF BORIC ACID AND RESVERATROL ON CELL INVASION}

To investigate the effect of boric acid and resveratrol on cell invasion, the intensity of MMP-9 protein expressions was analyzed immunocytochemically between the groups and H-Score analyses were done (Figure 3). MMP-9 immunoreactivity levels were found to be decreased in BA and BA+RES groups, compared to the control group (respectively $p=0,008 p=0,000$ ), while no change was recorded in the RES group $(\mathrm{p}=0,181)$.

\subsection{EFFECT OF BORIC ACID AND RESVERATROL ON CELL MIGRATION}

MCF-7 cells were cultured in a 24-well plate and waited until they became confluent, a wound field was generated in the middle of each well and the administrations were done for BA, BA + RES and RES groups. No administration was performed for the control group. To analyze cell migration tendency, the groups were photographed from the wound fields at the time points of $0,12,24,36$ and 48 hours. A complete wound healing was observed at the time point of 36 hours in the control and RES groups and velocity and organization of wound healing was the same in the RES group as the control group. In BA and BA+RES groups, the wound field was not healed until the time point of 48 hours and the cell migration to the wound field ceased, besides no healing was observed in the wound field (Figure 4).

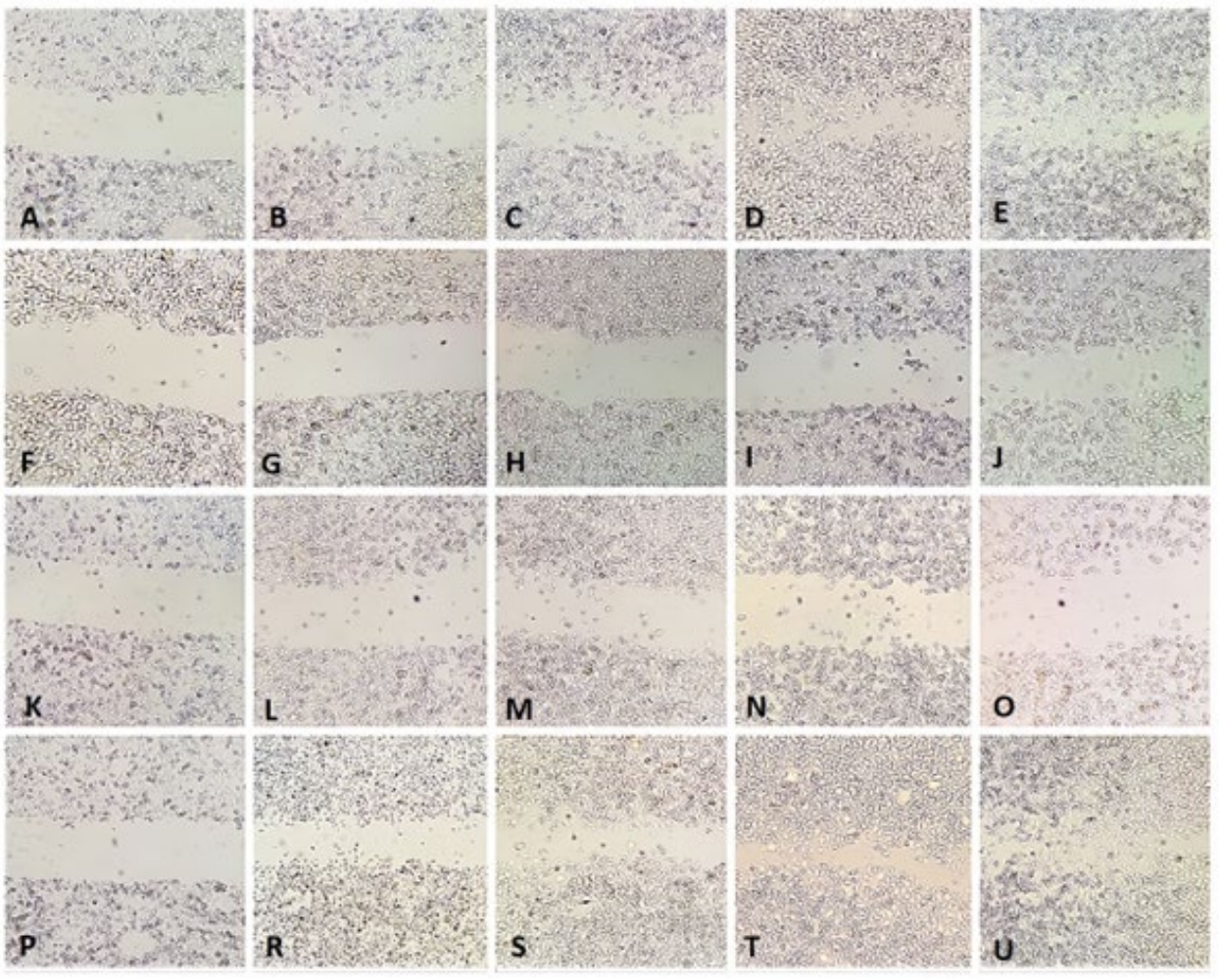

Figure 4 Evaluation of cell migration by wound healing assay (Scale bar $200 \mu \mathrm{m}$ ). Specifies vertical column groups, and horizontal row specifies application times. Control groups; A, B, C, D, E. Boric acid groups; F, G, H, I, J. Boric acid+resveratrol; K, L, M, N, O. Resveratrol; P, R, S, T, U. 0. Hours; A, F, K, P. 12. Hours; B, G, L, R. 24. Hours; C, H, M, S. 36. Hours; D, I, N, T. 48. Hours; E, J, O, U 


\section{DISCUSSION AND CONCLUSIONS}

Depending on the stage of the disease, the patient's properties and general health, cancer treatment might include several options such as surgery, radiation therapy, hormonal therapy, chemotherapy, goal-directed therapy, or alternative medicine. Alternative medicine is among the methods that aims to improve the immune system and support the main treatment, yet its reliability and efficiency is not proven by controlled experiments. Up to this day, several anti-cancer substances used in alternative medicine have been determined, produced, and tested; and 70\% of the anti-cancer medicine that is being used is obtained from natural resources Karikas (2010). There are also studies regarding boron not having a carcinogenic effect or rather it is accelerating carcinogenesis Yalcin and Abudayyak (2020). It has been shown that many boron products and its compounds have cytotoxic effects on rats and humans, as well as boron's effects on the migration, invasion and epithelialmesenchymal transition capabilities of cancer cells have not yet been able to be clarified. In this study we present, the $\mathrm{IC}_{50}$ dose, which is accepted as the toxic dose of applying boric acid to MCF-7 breast cancer cells, has been investigated and identified as $30 \mu \mathrm{M}$. The identified dose has been used in establishing the treatment groups and boron's effect on the migration, invasion and EMT tendencies of MCF-7 cells has been compared to resveratrol, in which several scientific studies report that it decreases the migration, invasion and epithelial-mesenchymal transition tendencies of cells.

It is known that E-Cadherin is a protein that is closely involved in the invasion and metastasis of human malignant tumor cells and the inactivation of it plays an important role in the development of the tumor Lee et al. (2015). It has been observed that with the loss of E-Cadherin, EMT is induced and in malignant differentiated carcinomas of different cancers, the E-Cadherin expression is either decreased or completely gone Graff et al. (1995). In our study, there was a significant increase in the RES group when the E-Cadherin immunoreactivity of cells were compared to the control group. However, the fact that there was no significant increase in BA and BA+ RES groups, compared to the CONT group, has shown that BA does not change the E-Cadherin expression in MCF-7 cells on its own and that RES might have a negative effect on the repressive property of E-Cadherin protein expression. It has been shown in our study and the other studies in literature that resveratrol treatment on MCF-7 cells decreases E-Cadherin expressions Shi et al. (2013), Sun et al. (2019) . In spite of this, our study is among the lead studies that show the negative effect on E-Cadherin protein expressions that BA has on cancer cells.

Vimentin, a member of the intermediate filament protein family, is highly expressed in normal mesenchymal cells and is known to maintain cellular integrity and provides resistance against stress. An increase of Vimentin expression has been reported in various epithelial cancers including prostate cancer, gastrointestinal tumors, central nervous system tumors, breast cancer, malignant melanoma, lung cancer and other cancer types. The over-expression of Vimentin in cancer is well associated with increased tumor growth, invasion, and poor prognosis Satelli and Li (2011). In various studies, increased E-Cadherin expression level and an increase in Vimentin expression in MCF-7 cells were associated with inhibition of poor prognosis and decreased EMT Wang et al. (2020). In our study, along with the similarity between the RES-CONT groups, a slight increase was observed in the BA group when the BA-CONT groups were compared $(p>0,05)$. Nonetheless, when the BA+RES group was compared to the CONT group, it was observed that there was an increase in Vimentin expression and this increase gave statistically significant $p$ - 
value $(\mathrm{p}=0,008)$. This result of our study makes us think that administration of resveratrol or boric acid alone to MCF-7 cells for 48 hours, was not effective in the change of Vimentin expression with the applied doses. In literature, there are studies that report the decrease of Vimentin expression subsequent to the resveratrol treatment. In 2011, Vergara et al., have reported that treatment of resveratrol for 24 hours at the dose of $25 \mu \mathrm{M}$ of MCF-7 cells led to a decrease in Vimentin expression, whereas, in 2013, Tsai et al., did not observe any differences between resveratrol (RES) and control groups when applied at the dose of $20 \mu \mathrm{M}$ for 24 hours in MCF-7 cells Tsai et al. (2013), Vergara et al. (2011). Our results support the finding by Tsai et al. It is thought that the difference between our finding and the study of Vergara et al. may be caused by the different doses and times that were applied. According to our result, while BA and RES alone did not change Vimentin expression at these durations and doses, it is thought that when BA+RES is applied together, it may cause Vimentin expression which is associated with poor prognosis.

Cancer cells frequently excrete MMPs and serine protease that are able to degrade extracellular matrix proteins. MMP-2 and MMP-9 are highly expressed in malignant tumors and make cell migration easier by playing a role in the degrading the extracellular matrix which is an important component of basal membrane that leads to cancer metastasis. In an in vivo study in rats treated with fucoidan in 2019, He et al., associated with the decrease of MMP-9 expression, with increased apoptosis of breast cancer cells and decreased EMT capabilities Xue et al. (2019). It has been observed in our study that the MMP-9 immunoreactivities of RES and CONT groups were similar ( $p=0,181)$. In the year of 2021, Chang et al. (2021) have reported that applying $50 \mu \mathrm{M}$ of Resveratrol for 24 hours causes a significant decrease in the MMP-9 expression of cancer cells Chang et al. (2021). Likewise, in the year of 2016, Park et al., have shown that there was a significant decrease in the MMP-9 expressions of breast cancer cells when treated with $10 \mu \mathrm{M}$ of resveratrol, that were loaded to pieces of gold, for 24 hours Park et al. (2016). In our study, the applied $50 \mu \mathrm{M}$ of resveratrol for 48 hours did not change the MMP-9 expression. Although the used dose was the same as the one used by Chang et al., it did not have the same effect probably due to different cell lines being used. In a similar manner, Park et al., applied resveratrol in a lower dose and time, but they applied it indirectly in the form of gold-coated nanoparticles. It is thought that the difference may be due to the fact that nanoparticles enter the cell more easily and effectively. We found that BA significantly reduced MMP-9 immunoreactivity when the BA group was compared to the CONT group ( $p=0,008)$. Compared to the CONT group $(p=0,000)$, it has been observed that there was also a significant decrease in MMP-9 in the BA+RES group and this decrease was caused by BA. It is thought that applying 30 $\mu \mathrm{M}$ dose of BA for 48 hours to the MCF-7 cells may repress cell invasion by decreasing MMP-9 expression. Our wound healing experiment results also support the decrease in MMP-9 protein expression. When looked at the results of this experiment, for CONT and RES groups, the wound area had completely healed, and the cells had completed the migration to the wound field at the end of 48 hours. However, in the BA and BA+RES groups, no cell migration was recorded throughout 48 hours and at the end of the $48^{\text {th }}$ hour and the wound field remained as it was at the 0th hour. According to these results, when BA alone or with Resveratrol is applied to MCF-7 cells in vitro, it seems to inhibit cell migration.

The effect of BA and RES, both on their own and combined, on the morphologic characteristics of MCF-7 cells was evaluated with phase-contrast microscope both before and after treatment. The negative effects of boric acid on cell morphology were seen in both the BA group and BA+RES group. Similar to the changes in mitotic cells, there was an increase of spheric shape and nuclear condensation in cells. When 
it comes to the RES group, besides the amount of increase in nuclear condensation, the distribution of sphere-shaped cells was similar to the CONT group. In their study carried out in 2020, Josifovska et al., have shown with electron microscopic methods that there was an increase in the number of autophagic vacuoles in resveratrol treated cancer cells Josifovska et al. (2020). In the study we present, there was also an increase in intracellular vacuolization for both the RES group and BA and BA+ RES groups. As shown in Josifovska et al. study, this increase is thought to be caused by the cells' autophagic or apoptotic differences. The effects boric acid has on cell autophagy and apoptosis must be evaluated further with advanced molecular methods.

In conclusion, it has been observed that BA does not affect the EMT capabilities of MCF-7 cells in terms of E-Cadherin and Vimentin protein expressions, whereas it does affect cell migration both by decreasing MMP-9 protein expression as well as inhibiting cell migration in vitro. Our study can be accepted as a lead study in terms of the effects boric acid has on cell migration and EMT.

\section{REFERENCES}

Aydin, H. E. Gunduz, M. Kizmazoglu, K. C. Kandemir, T. and Arslantas, A. (2021) Cytotoxic Effect of Boron Application on Glioblastoma Cells, Turk. Neurosurg., vol. 31, no. 2, Retrieved from https://doi.org/10.5137/10195149.JTN.30316-20.1

Banfalvi, G. (2012) Metastatic view of breast cancer, Cancer and Metastasis Reviews, vol. 31, no. 3-4. Retrieved from https://doi.org/10.1007/s10555-012-93926

Barranco, W. T. Hudak, P. F. and Eckhert, C. D. (2007) Evaluation of ecological and in vitro effects of boron on prostate cancer risk (United States), Cancer Causes Control, vol. 18, no. 1, Retrieved from https://doi.org/10.1007/s10552006-0077-8

Baur, J. A. and Sinclair, D. A. (2006) Therapeutic potential of resveratrol : The in vivo evidence, Nature Reviews Drug Discovery, vol. 5, no. 6.. Retrieved from https://doi.org/10.1038/nrd2060

Chang, W. et al., (2021) Resveratrol inhibited the metastatic behaviors of cisplatinresistant human oral cancer cells via phosphorylation of ERK/p-38 and suppression of MMP-2/9, J. Food Biochem., no. November 2020, pp. 1-9, Retrieved from https://doi.org/10.1111/jfbc.13666

Chen, K. Y. Chen, C. C. Chang, Y. C. and Chang, M. C. (2019) Resveratrol induced premature senescence and inhibited epithelial-mesenchymal transition of cancer cells via induction of tumor suppressor Rad9, PLoS One, vol. 14, no. 7, Retrieved from https://doi.org/10.1371/journal.pone.0219317

Devirian, T. A. and Volpe, S. L. (2003) The Physiological Effects of Dietary Boron, Crit. Rev. Food Sci. Nutr., vol. 43, no. 2, Retrieved from https://doi.org/10.1080/10408690390826491

Dillekås, H. Rogers, M. S. and Straume, O. (2019) Are 90\% of deaths from cancer caused by metastases ? Cancer Med., vol. 8, no. 12, Retrieved from https://doi.org/10.1002/cam4.2474

Farahani, E. et al. (2014) Cell adhesion molecules and their relation to (cancer) cell stemness, Carcinogenesis, vol. 35, no. 4.. Retrieved from https://doi.org/10.1093/carcin/bgu045 
Gharagozloo, M. et al., (2015) CLINICAL STUDY Immune-mediated cochleovestibular disease, Bratislava Med. J., vol. 116, no. 5, pp. 296-301,

Global Cancer Observatory, (2021) Estimated number of deaths en 2020, worldwide, males, all ages, vol. 996, p. Obtenido el 16 de mayo del 2021, [Online]. Available : https://gco.iarc.fr/

Graff, J. R. et al., (1995) E-Cadherin Expression Is Silenced by DNA Hypermethylation in Human Breast and Prostate Carcinomas, Cancer Res., vol. 55, no. 22,

Hacioglu, C. Kar, F. Kacar, S. Sahinturk, V. and Kanbak, G. (2020) High Concentrations of Boric Acid Trigger Concentration-Dependent Oxidative Stress, Apoptotic Pathways and Morphological Alterations in DU-145 Human Prostate Cancer Cell Line, Biol. Trace Elem. Res., vol. 193, no. 2, Retrieved from https://doi.org/10.1007/s12011-019-01739-x

He, X. Xue, M. Jiang, S. Li, W. Yu, J. and Xiang, S. (2019) Fucoidan promotes apoptosis and inhibits EMT of breast cancer cells, Biol. Pharm. Bull., vol. 42, no. 3, pp., 442-447. Retrieved from https://doi.org/10.1248/bpb.b18-00777

Jones, J. L. Glynn, P. and Walker, R. A. (1999) Expression of MMP-2 and MMP-9, their inhibitors, and the activator MT1- MMP in primary breast carcinomas, J. Pathol., vol. 189, no. 2, Retrieved from https://doi.org/10.1002/(SICI)10969896(199910)189:2<161::AID-PATH406>3.0.CO;2-2

Josifovska, N. et al., (2020) Resveratrol as inducer of autophagy, pro-survival, and anti-inflammatory stimuli in cultured human RPE cells, Int. J. Mol. Sci., vol. 21, no. 3, Retrieved from https://doi.org/10.3390/ijms21030813

Karikas, G. A. (2010) Anticancer and chemopreventing natural products: Some biochemical and therapeutic aspects, Journal of B.U.ON., vol. 15, no. 4. Retrieved from https://www.researchgate.net/profile/GeorgeKarikas /publication/49750231_Anticancer_and_chemopreventing_natural _products_Some_biochemical_and_therapeutic_aspects/links/0c96053a46 85fd6b93000000/Anticancer-and-chemopreventing-natural-productsSome-biochemical-and-therapeutic-aspects.pdf

Lee, A. Y. L. et al., (2015) Curcumin Inhibits Invasiveness and EpithelialMesenchymal Transition in Oral Squamous Cell Carcinoma Through Reducing Matrix Metalloproteinase 2, 9 and Modulating p53-E-Cadherin Pathway, Integr. Cancer Ther., vol. 14, no. 5, pp. 484-490, Retrieved from https://doi.org/10.1177/1534735415588930

Leon-Galicia, I. et al., (2018) Resveratrol decreases Rad51 expression and sensitizes cisplatin-resistant MCF-7 breast cancer cells, Oncol. Rep., vol. 39, no. 6, Retrieved from https://doi.org/10.3892/or.2018.6336

Mahjoubin-Tehran, M. et al., (2020) Peptide decoys : à new technology offering therapeutic opportunities for breast cancer, Drug Discovery Today, vol. 25, no. 3.. Retrieved from https://doi.org/10.1016/j.drudis.2020.01.010

Moore, J. A. (1997) An assessment of boric acid and borax using the IEHR evaluative process for assessing human developmental and reproductive toxicity of agents, Reprod. Toxicol., vol. 11, no. 1, Retrieved from https://doi.org/10.1016/S0890-6238(96)00204-3

Nielsen, F. H. (1994) Biochemical and physiologic consequences of boron deprivation in humans, in Environmental Health Perspectives, vol. 102, no. SUPPL. 7. Retrieved from https://doi.org/10.1289/ehp.94102s759

Numata, M. Cross, J. R. Hospital, H. Watanabe, T. and Yamamoto, N. (2012) The clinical significance of SWI / SNF complex in pancreatic cancer, no. November, Retrieved from https://doi.org/10.3892/ijo.2012.1723 
Park, S. Y. Chae, S. Y. Park, J. O. Lee, K. J. and Park, G. (2016) Gold-conjugated resveratrol nanoparticles attenuate the invasion and MMP-9 and COX-2 expression in breast cancer cells, Oncol. Rep., vol. 35, no. 6, Retrieved from https://doi.org/10.3892/or.2016.4716

Pawa, S. and Ali, S. (2006) Boron ameliorates fulminant hepatic failure by counteracting the changes associated with the oxidative stress, Chem. Biol. Interact., vol. 160, no. 2, Retrieved from https://doi.org/10.1016/j.cbi.2005.12.002

Reymond, N. D'Água, B. B. and Ridley, A. J. (2013) Crossing the endothelial barrier during metastasis, Nature Reviews Cancer, vol. 13, no. 12.. Retrieved from https://doi.org/10.1038/nrc3628

Satelli, A. and Li, S. (2011) Vimentin in cancer and its potential as a molecular target for cancer therapy, Cellular and Molecular Life Sciences, vol. 68, no. $18 .$. Retrieved from https://doi.org/10.1007/s00018-011-0735-1

Schmidt, B. Ferreira, C. Passos, C. L. A. Silva, J. L. and Fialho, E. (2020) Resveratrol, curcumin and piperine alter human glyoxalase 1 in mcf-7 breast cancer cells, Int. J. Mol. Sci., vol. 21, no. 15, Retrieved from https://doi.org/10.3390/ijms21155244

Scorilas, A. et al., (2001) Overexpression of matrix-metalloproteinase-9 in human breast cancer : A potential favourable indicator in node-negative patients, Br. J. Cancer, vol. 84, no. 11, Retrieved from https://doi.org/10.1054/bjoc.2001.1810

Shi, X. P. et al., (2013) Resveratrol sensitizes tamoxifen in antiestrogen-resistant breast cancer cells with epithelial-mesenchymal transition features, Int. J. Mol. Sci., vol. 14, no. 8, Retrieved from https://doi.org/10.3390/ijms140815655

Signorelli, P. and Ghidoni, R. (2005) Resveratrol as an anticancer nutrient: Molecular basis, open questions and promises, Journal of Nutritional Biochemistry, vol. 16, no. 8.. Retrieved from https://doi.org/10.1016/j.jnutbio.2005.01.017

Sun, Y. et al., (2019) Resveratrol inhibits the migration and metastasis of MDA-MB231 human breast cancer by reversing TGF- $\beta 1$-induced epithelialmesenchymal transition, Molecules, vol. 24, no. 6, Retrieved from https://doi.org/10.3390/molecules24061131

Tsai, J. H. et al., (2013) 3,5,4'-Trimethoxystilbene, a natural methoxylated analog of resveratrol, inhibits breast cancer cell invasiveness by downregulation of PI3K/Akt and Wnt/ $\beta$-catenin signaling cascades and reversal of epithelialmesenchymal transition, Toxicol. Appl. Pharmacol., vol. 272, no. 3, Retrieved from https://doi.org/10.1016/j.taap.2013.07.019

Vergara, D. et al., (2011) Resveratrol inhibits the epidermal growth factor-induced epithelial mesenchymal transition in MCF-7 cells, Cancer Lett., vol. 310, no. 1, Retrieved from https://doi.org/10.1016/j.canlet.2011.04.009

Wang, X. et al., (2020) Trichostatin A reverses epithelial-mesenchymal transition and attenuates invasion and migration in MCF-7 breast cancer cells, Exp. Ther. Med.,. Retrieved from https://doi.org/10.3892/etm.2020.8422

Westermarck, J. and Kähäri,V. (1999) Regulation of matrix metalloproteinase expression in tumor invasion, FASEB J., vol. 13, no. 8, Retrieved from https://doi.org/10.1096/fasebj.13.8.781

$\mathrm{Xu}$, J. et al., (2017) Resveratrol reverses Doxorubicin resistance by inhibiting epithelial-mesenchymal transition (EMT) through modulating PTEN/Akt 
signaling pathway in gastric cancer, J. Exp. Clin. Cancer Res., vol. 36, no. 1, Retrieved from https://doi.org/10.1186/s13046-016-0487-8

Yalcin, C. O. and Abudayyak, M. (2020) Effects of boric acid on cell death and oxidative stress of mouse TM3 Leydig cells in vitro, J. Trace Elem. Med. Biol., vol. 61, Retrieved from https://doi.org/10.1016/j.jtemb.2020.126506

Zhang, Q. et al., (2019) ACE2 inhibits breast cancer angiogenesis via suppressing the VEGFa/VEGFR2/ERK pathway, J. Exp. Clin. Cancer Res., vol. 38, no. 1, Retrieved from https://doi.org/10.1186/s13046-019-1156-5

Özkara, G. Öztürk, O. and Aydoğan, H. Y. (2020) Kanser ve Metastaz: Hücre Adezyon Molekülleri ve Hücreler Arası Bağlantıların Önemi, Experimed, vol. 10, no. 1, pp. 38-48, Retrieved from https://doi.org/10.26650/experimed.2020.0003 